\title{
Graphene derivative coated QCM-based gas sensor for volatile organic compound (VOC) detection at room temperature
}

\author{
Monika Gupta, Nurul Athirah, Huzein Fahmi Hawari \\ Department of Electrical and Electronic Engineering, Center of Innovative Nanostructures and Nanodevices (COINN), \\ Universiti Teknologi PETRONAS, Malaysia
}

\begin{tabular}{l}
\hline Article Info \\
\hline Article history: \\
Received Oct 10, 2019 \\
Revised Dec 13, 2019 \\
Accepted Dec 27, 2019
\end{tabular}

Keywords:

Gas sensor

Graphene

Quartz crystal microbalance

Room temperature

Volatile organic compound

\begin{abstract}
Volatile organic compounds (VOCs) affect our daily life through their emission from very common sources such as plants, building materials, paints, pesticides, and fossil fuel burning. The detection of VOCs at room temperature is a prime requirement. The graphene-based gas sensor has the potential to detect these VOC gases due to its attractive features such as high mobility and large surface area. In this work, a graphene-derivative is prepared as a sensing material in order to detect acetone. The thin film of graphene-derivative is prepared by a drop-cast method on a quartz crystal microbalance (QCM) sensor followed by drying in the room environment conditions. The prepared graphene-derivative and thin films are characterized structurally and morphologically by standard microscopic techniques such as FESEM, EDX, and Raman spectroscopy. The electrical parameters such as mobility and resistivity are measured using Hall-effect measurements at room temperature. The response and recovery time of the graphenederivative based $10 \mathrm{MHz}$ QCM sensor are found to be $23 \mathrm{~s}$ and $20 \mathrm{~s}$, respectively. This highly sensitive graphene-based gas sensor with good reversibility can be employed for human health and environment safety applications.
\end{abstract}

Copyright $\odot 2020$ Institute of Advanced Engineering and Science. All rights reserved.

\section{Corresponding Author:}

Huzein Fahmi Hawari,

Department of Electrical and Electronic Engineering,

Center of Innovative Nanostructures and Nanodevices (COINN),

Universiti Teknologi PETRONAS,

32610 Seri Iskander, Perak Darul Ridzuan, Malaysia.

Email: huzeinfahmi.hawari@utp.edu.my,

\section{INTRODUCTION}

Health-monitoring by analyzing the human breath is emerging nowadays. The exhaled human breath is a combination of about 3500 different volatile organic compounds (VOCs). Particularly, a single person's breath consists of approximately 500 various types of VOCs in the range of parts per million (ppm) or parts per billion (ppb) range or parts per trillion (ppt) [1,2]. The detection of VOCs, therefore, becomes important for detecting serious diseases such as lung cancer, breast cancer, asthma, and diabetes [3]. Among the detection devices or sensors, quartz crystal microbalance (QCM) is highly preferred sensing devices because it is robust, cost-effective, highly mass sensitive and very accurate for the detection of analyte gas [3, 4]. QCM sensor contains a quartz crystal wafer sandwiched between two metal-coated (gold, silver) electrodes. The change of resonant frequency of QCM is based on the mass of the absorbed molecule on the QCM electrode surface.

In the sensor's architecture, sensing material plays a very crucial role in responding to the gas molecules. As a sensing material, several pristine and composite materials such as zinc oxide ( $\mathrm{ZnO})$ [5], tin oxide $\left(\mathrm{SnO}_{2}\right)$ [6], titanium dioxide (TiO2) [7], polyaniline (PANI) [8], carbon nanotubes (CNTs) [9], graphene [10] and $\mathrm{ZnO}-\mathrm{CuO}$ [11] have been widely investigated. Among these sensing materials, graphene 
has attracted the research community due to its unique properties at room temperature for instance, large surface area $\left(2630 \mathrm{~m}^{2} \mathrm{~g}^{-1}\right)$ for molecular adsorption, outstanding thermal $\left(\sim 5000 \mathrm{~W} \cdot \mathrm{m}^{-1} \cdot \mathrm{k}^{-1}\right)$ and

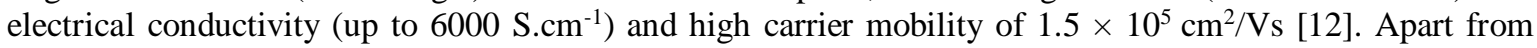
graphene, the graphene derivative like reduced graphene oxide (rGO) is also being explored for gas sensing applications owing to its facile preparation and novel applications for gas molecule detection [13, 14]. Many gas sensors based on rGO have been recently reported for the detection of various gases, such as $\mathrm{CH}_{4}$, $\mathrm{H}_{2}, \mathrm{CO}_{2}, \mathrm{CO}, \mathrm{NO}_{2}, \mathrm{NH}_{3}$, and $\mathrm{H}_{2} \mathrm{~S}[12,15-18]$. But, the sensor with fast response and recovery time at room temperature is limitedly reported.

In this work, we investigated the thin film of reduced graphene oxide as sensing material on a QCM sensor for VOC gas detection at room temperature. The rGO suspension is initially prepared by reducing the aqueous suspension of GO paste using ascorbic acid (L-AA). The thin films of rGO was prepared by the drop-cast method followed by drying at room temperature. The contaminants-free wrinkled morphology of rGO thin films with multilayer graphene structure, high mobility of $\sim 2 \times 10^{4} \mathrm{~cm}^{2} / \mathrm{Vs}$ and low resistivity of $\sim 4 \times 10^{-1} \Omega \mathrm{cm}$, enhance the absorption of acetone molecules on its surface. This leads to a fast response from the QCM gas sensor with rGO sensing material. Using as-prepared rGO thin sensing films, the QCM-gas sensors exhibiting fast response and recovery time of $\sim 20-30$ s are demonstrated.

\section{RESEARCH METHOD}

Graphene oxide (GO) paste (95 wt\% purity) used in this study was purchased from Graphenea (San Sebastian, Spain). Ascorbic acid, Ethanol (AR, $\geq 95 \%$ wt purity) and Acetone (AR, $\geq 95 \%$ wt purity) were purchased by Sigma Aldrich. All chemicals are analytical grade, no further purification is required for conducting experiments. De-ionized (DI) water is used in all preparations. For preparing an aqueous suspension of reduced-graphene oxide ( $\mathrm{rGO}), 2.5 \mathrm{ml}$ of $\mathrm{GO}$ paste $\left(\mathrm{M}_{\mathrm{w}}=4 \mathrm{mg} / \mathrm{ml}\right)$ was added in $25 \mathrm{ml}$ of DI water. Then, $5 \mathrm{mg}$ of ascorbic acid was slowly added into as-prepared aqueous rGO suspension followed by ultrasonication for 15 minutes. The prepared suspension was then stirred for 1 hour at $65{ }^{\circ} \mathrm{C}$. After stirring, the $\mathrm{rGO}$ suspension is rinsed several times with DI water using a centrifuge and filtered in order to remove the ascorbic acid as shown in Figure 1(a).

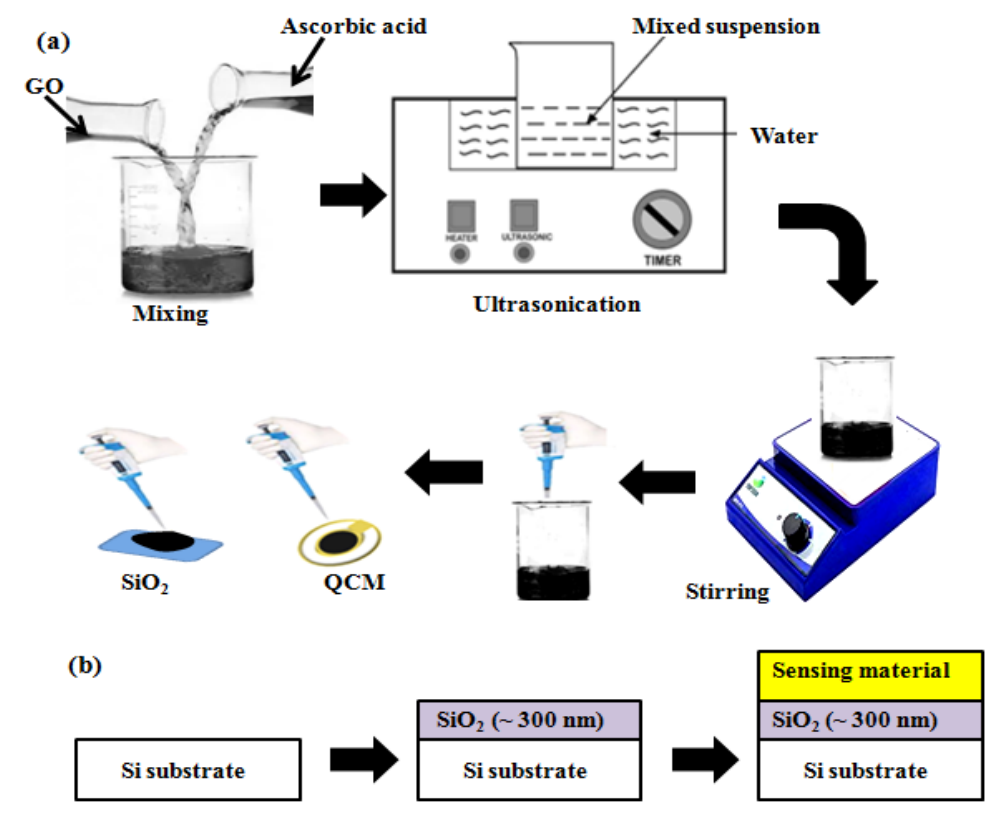

Figure 1. (a) Schematic illustration for preparation of rGO-coated QCM sensor, (b) Process flow for preparation of $\mathrm{rGO}$ thin film on $\mathrm{SiO}_{2}-\mathrm{Si}$ substrate

The surface morphology and structural characteristic were inspected by Field emission scanning electron microscopy (FESEM, Zeiss supra 55VP), energy-dispersive X-ray spectroscopy (EDX) and Raman spectroscopy (Horiba Jobin Yvon HR800, excitation wavelength of $514 \mathrm{~nm}$ ). Raman spectroscopy is a non-destructive and direct technique to measure the chemical and structural characteristics of the molecules 
in the sample. The electrical parameters such as mobility and conductivity were measured using Hall-effect. For the above microscopic characterizations, the thin films of rGO were prepared by the drop-cast method on the target substrate such as $\mathrm{SiO}_{2}$. The $\mathrm{SiO}_{2}$ substrate was prepared on a p-type $\mathrm{Si}$ wafer (resistivity of $0.001-0.005 \Omega \mathrm{m}$ ). Initially, the Si wafer was cleaned using the RCA method in order to remove possible contaminants and native oxide $[19,20]$. Then, an oxide layer $(200-300 \mathrm{~nm})$ was grown using the dry oxidation technique at $1100{ }^{\circ} \mathrm{C}$. The $\mathrm{Si}-\mathrm{SiO}_{2}$ substrates were later sliced into the pieces of size $2 \mathrm{~cm} \times 2 \mathrm{~cm}$. The process flow for $\mathrm{rGO}$ thin film is illustrated in Figure 1(b).

For preparing the rGO-coated QCM sensor, $1 \mu \mathrm{L}$ of as-prepared $\mathrm{rGO}$ suspension was extracted from the beaker using a high precision micropipette. Then, a sub-micron layer of rGO was drop cast on the gold plated AT-cut $10 \mathrm{MHz}$ QCM electrode surface. The coated QCM was then dried at room ambient for at least $24 \mathrm{~h}$. Before thin-film development, the bare QCM was cleaned with anhydrous ethanol (AR) and DI water using ultrasonication (15 minutes each) [21]. A schematic illustration of preparing of rGO coated QCM sensor shown in Figure 1(a).

The gas sensing experiment is performed by using a custom made gas sensing setup at room temperature. Figure 2 illustrates the QCM based gas sensing experimental setup. The rGO coated QCM is placed in a QCM holder. The QCM holder is then connected to a frequency counter (FQ4, jlm Innovation Denmark). The output of the frequency meter was connected to a compatible computer via an RS-232 serial communication port. Multisense software is used to get the sensing characteristics (time vs. frequency).

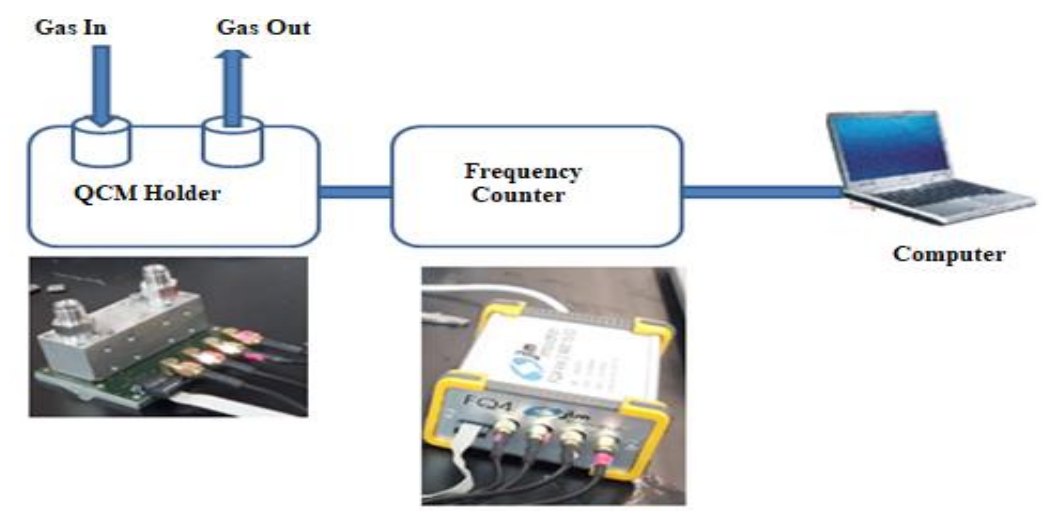

Figure 2. Experimental setup for QCM based gas sensing

In typical sensing operation, the sensor holder chamber was initially filled with air to obtain the baseline. Then, $500 \mathrm{ppm}$ and $100 \mathrm{ppm}$ acetone vapors were infused into the chamber. After the infusion of acetone vapors, the frequency-shifted abruptly at the beginning. It was then gradually started to reach the steady-state value. This expresses that the maximum number of acetone molecules has been absorbed on the surface of the rGO film [22]. On the absorption of molecules, the mass of absorbate is increased at the sensor surface, thereby shifting in the resonant frequency takes place in proportion to the mass of absorbate molecules (Dominant phenomenon of QCM sensing [3, 23]). For observing the reversibility and reproducibility the exposure of acetone vapor is replaced by air then, the rGO coated QCM will achieve the baseline frequency. If the process continues for various cycles, the sensor indicates good reversibility and reproducibility.

\section{RESULTS AND DISCUSSION}

\subsection{Morphological and Structural Analysis}

Figure 3 illustrates the morphology of rGO films using FESEM. Figure 3(a) shows a wrinkled surface showing that graphene layers are distorted due to the linkage of the residual oxygen after the thermal reduction. The reduced graphene with wrinkled morphology can absorb the analyte molecule effectively. Zhang et al. [24] also reported similar morphology. The high magnification image of the rGO surface is shown in Figure 3(b). The presence of additional elements in the rGO sample was investigated using the EDX detector. Figure 4 depicts the EDX mapping. Carbon, oxygen, silicon were detected on the surface of rGO as shown in Figure 5(a), 5(b), 5(c), respectively. The detected amount of the elements in rGO thin film sample is shown in Table 1. The mass ratio of $\mathrm{C}: \mathrm{O}$ of $\mathrm{GO}$ and $\mathrm{rGO}$ was observed to be 7:5 and 9:3, respectively. It can be seen that hydrogen, nitrogen, and sulfur were absent. It was also observed that the 
amounts of oxygen and carbon contents of the rGO sample were reduced in comparison to the GO sample. These results indicate that the ascorbic acid has reduced the GO into rGO to a certain extent. Similar observations were also reported by Eluyemi et al. [25].

Figure 6 shows the Raman spectrum of the rGO sample. The D- and G-peaks were found to be at Raman shift of $\sim 1350 \mathrm{~cm}^{-1}$ and $\sim 1580 \mathrm{~cm}^{-1}$, respectively. The positions of D- and G-band are significantly dependent on the defects, edges, disorder, grain size and microstructure of the graphene materials. The D-band of graphene indicates to the defects and G-band represents the $\mathrm{sp}^{2}$ atomic arrangement of carbon atoms of graphene layers $[26,27]$. The relative intensity ratio $I_{D} / I_{G}$ for $\mathrm{rGO}$ was found to be 1.295 indicates the presence of defects in rGO film [28]. Thus, this defective nature of carbon structure is primarily accountable for the adsorption of the VOC gas molecules. Such defects are favorable for VOC gas sensing [29]. The second-order D-peak (i.e. 2D-peak) was observed to be located at $\sim 2655 \mathrm{~cm}^{-1}$ Raman shift. The position, shape of $2 \mathrm{D}$-peak and $I_{2 D} / I_{G}$ intensity ratio are used to discriminate the monolayer and few-layer graphene in the structure. The $I_{2 D} / I_{G}$ intensity ratio was found to be 0.255 for the rGO sample, indicating that it has few-layer graphene features, similar results are also reported by Antony et al. [30].
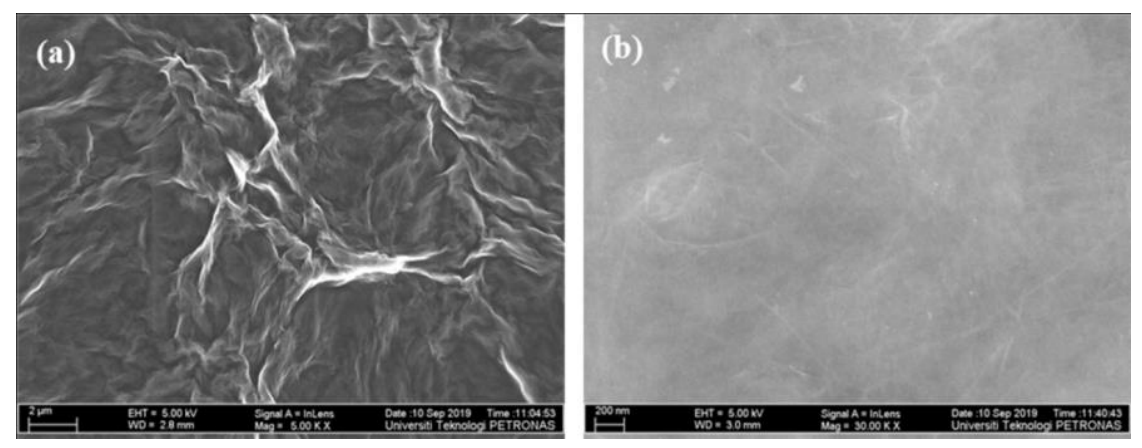

Figure 3. FESEM images of rGO thin films at lower magnification (a) $2 \mu \mathrm{m}$ and at higher magnification, (b) $200 \mathrm{~nm}$

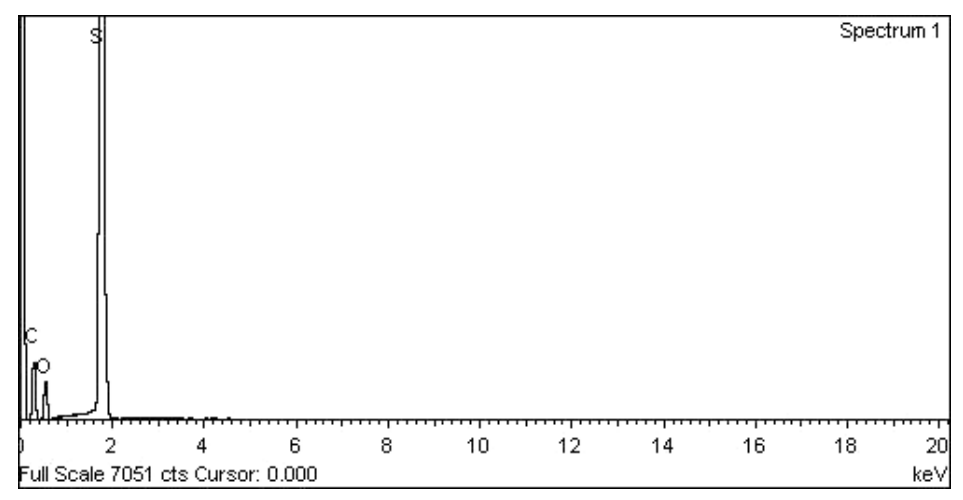

Figure 4. EDX spectra of rGO thin film

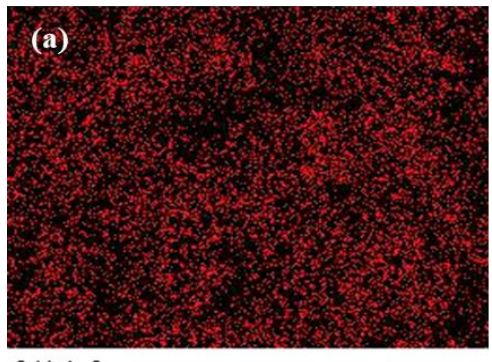

CKa1_2

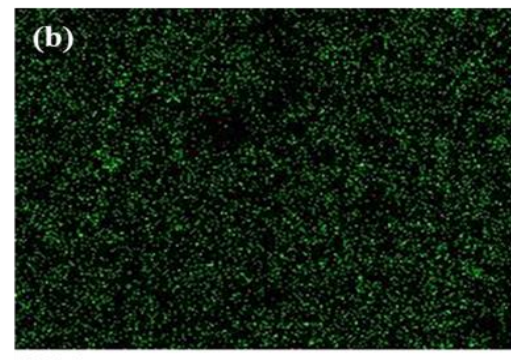

O Ka1

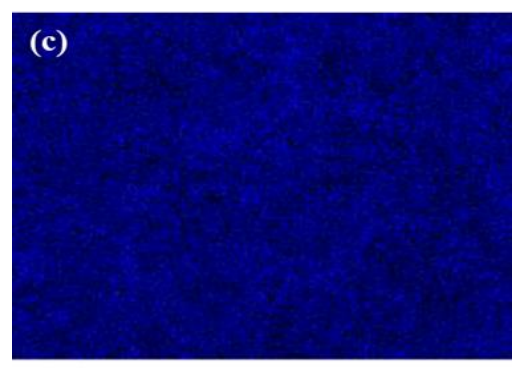

Si Ka1

Figure 5. EDX mapping of rGO thin film 
Table 1. Elemental composition of rGO determined by EDX

\begin{tabular}{ccc}
\hline Element & Weight $\%$ & Atomic\% \\
\hline C K & 45.57 & 61.7 \\
O K & 15.27 & 15.53 \\
Si K & 39.16 & 22.70 \\
\hline
\end{tabular}

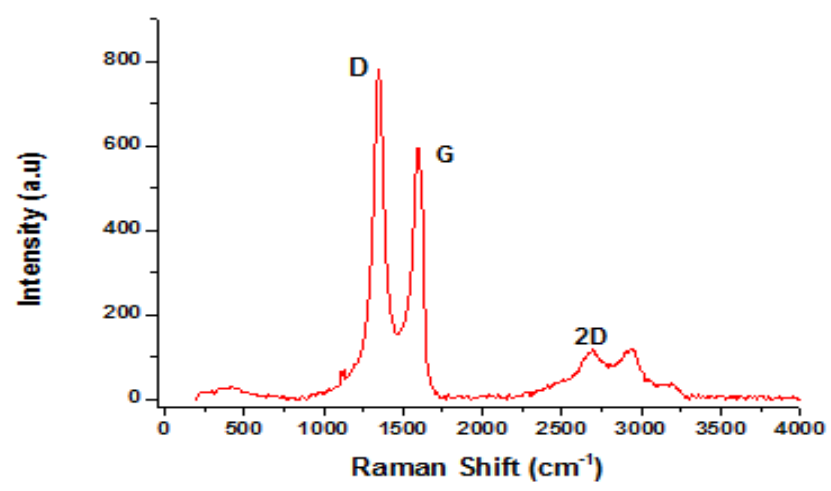

Figure 6. RAMAN spectrum of rGO thin film on $\mathrm{SiO}_{2} / \mathrm{Si}$ substrate

\subsection{Electrical Parameters}

The electrical parameter such as mobility and conductivity of $\mathrm{rGO}$ film on $\mathrm{SiO}_{2}(300 \mathrm{~nm}) / \mathrm{Si}$ substrate were measured using Hall-effect measurement. The mobility and the resistivity of rGO film on $\mathrm{SiO}_{2}$ $(300 \mathrm{~nm}) / \mathrm{Si}$ substrate were found to be $2.228 \times 10^{4} \mathrm{~cm}^{2} \mathrm{~V}^{-1} \mathrm{~s}^{-1}$ and $3.827 \times 10^{-1} \Omega \mathrm{cm}$, respectively. The carrier density was measured to be $-4.393 \times 10^{10} \mathrm{~cm}^{-2}$. Similar results were also reported by Novoselov et. al [31]. The electron mobility, resistivity and carrier density of a graphene-based film in the range of 500-20,000 $\mathrm{cm}^{2} / \mathrm{Vs}, 10^{-6} \Omega \mathrm{cm}$, and $10^{12} / \mathrm{cm}^{2}$, respectively are highly desirable for gas and vapor sensing operation at room temperature [32]. The Hall-effect results indicate that the prepared rGO material has the potential for gas and vapor sensor.

\subsection{Sensing Properties}

Figure 7(a) and 7(b) shows the response-recovery curve of rGO coated QCM for 500 ppm and 100 ppm acetone vapor at room temperature, respectively. The response of the sensor is expressed in frequency shift $\Delta f$ which can be calculated by $\Delta f=\left(f_{\text {air }}-f_{\text {gas }}\right)$, where $f_{\text {air }}, f_{\text {gas }}$ are the frequencies of QCM at airflow and gas flow (acetone vapor) conditions, respectively [33]. The response of the prepared QCM sensor was $3500 \mathrm{~Hz}$ and $200 \mathrm{~Hz}$ for $500 \mathrm{ppm}$ and $100 \mathrm{ppm}$, respectively. The frequency shift was found to be higher for a higher concentration of acetone vapor. A similar trend in the frequency response was achieved for the three cycles of gas flow at both concentrations. This suggests good reversibility and reproducibility of the developed sensor are achieved.
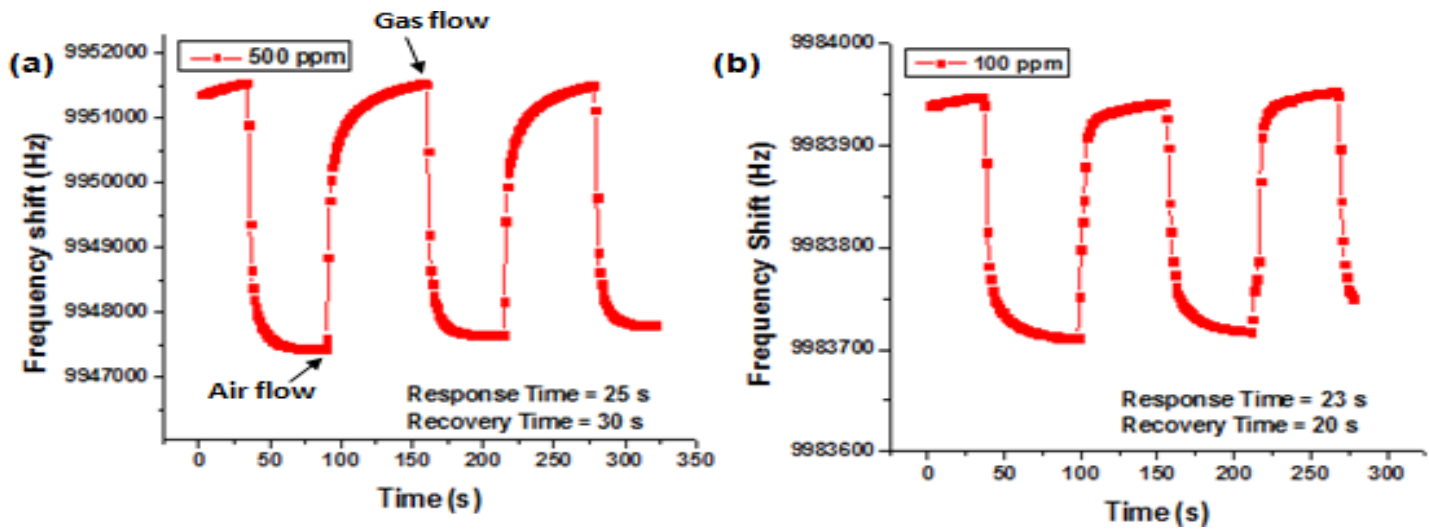

Figure 7. The frequency shift of rGO-based QCM sensor for acetone vapors at (a) 500 ppm concentration and (b) 100 ppm concentration 
The response time of the rGO coated QCM sensor for $500 \mathrm{ppm}$ was obtained to be $25 \mathrm{~s}$ whereas it was $23 \mathrm{~s}$ in the case of $100 \mathrm{ppm}$ of acetone vapor. The response time is the time taken in the relative change in frequency to reach $90 \%$ of the steady-state value [34]. The recovery time of the QCM sensor with rGO sensing materials was found to be $30 \mathrm{~s}$ and $20 \mathrm{~s}$ for 500 and $100 \mathrm{ppm}$, respectively. This short recovery time attributes to the weak van der walls bond between acetone molecule and rGO [14]. Thus, without annealing, the acetone vapor molecule can be removed (reversibility) from the rGO surface. This entails that acetone molecules can easily get absorbed/ desorbed at the surface of rGO thin film, indicating that the QCM sensor with as-prepared rGO sensing material has achieved a good response and recovery time.

\subsection{Related Mechanism}

The gas sensing principle depends on the change in mass of absorbate at the rGO-coated QCM electrode and the mass of absorbate depends on the number of graphene layers and agglomeration of rGO sheets spreading on QCM electrode $[13,14]$. Since as-prepared rGO thin film has aggregates, wrinkles and crumples along with multilayer graphene structure. Therefore, when the acetone vapor is exposed to the rGOcoated QCM, the acetone molecules cause van der walls interaction and hydrogen bonding between acetone molecule and $\mathrm{rGO}(\mathrm{COOH}$ group of graphene), leading to the change in mass of absorbate at surface of the QCM electrode [10]. Consequently, the variations in frequency shift are obtained. Since these van der walls bonds are naturally weak, so the absorbate can easily desorb on the air exposure. Such desorption of molecules indicates a good recovery of the sensing device.

\section{CONCLUSION}

In this work, we have successfully demonstrated graphene-derivative (rGO) based thin film as sensing material in the QCM gas sensor for acetone detection at room temperature. The thin film of rGO was prepared by the drop-cast method on the QCM electrode. The surface morphology, structural and electrical properties of as-prepared rGO material and thin films were analyzed using standard microscopic techniques and Hall-effect measurement. The wrinkled multilayer graphene film structure without possible contaminants indicates that the as-prepared $\mathrm{rGO}$ film surface is inducive to the absorption of gas vapor. The mobility of $2.228 \times 10^{4} \mathrm{~cm}^{2} / \mathrm{Vs}$ and resistivity of $3.827 \times 10^{-1} \Omega \mathrm{cm}$ of $\mathrm{rGO}$ thin film indicates the good electrical properties which can lead to a fast response from rGO-based QCM sensor. The developed QCM sensor with rGO thin film as sensing material showed good reversibility and reproducibility with good response ( $200 \mathrm{~Hz}$ for $100 \mathrm{ppm}$ and $3.5 \mathrm{kHz}$ for $500 \mathrm{ppm}$ ) for acetone vapors. Both response and recovery time were found to be $\sim 20-30 \mathrm{~s}$. With such potential outcomes, this simple, cost-effective rGO-based highly sensitive gas sensor can be fruitful to the applications such as human health and environment safety. Some further modifications in this work can give more promising results.

\section{ACKNOWLEDGEMENTS}

The authors would also like to thank Nur Hikmah, Wan Abdul Syaqur, Zhi Yan and Pradeep Kumar for technical support. The authors also acknowledged the GA scheme from the Center for Graduate Studies (CGS), UTP for financial support. This work was partially supported by the Yayasan UTP grant (015LC0-153).

\section{REFERENCES}

[1] A. Rydosz, "Sensors for Enhanced Detection of Acetone as a Potential Tool for Noninvasive Diabetes Monitoring," Sensors, vol. 18, no. 7, p. 2298, Jul. 2018.

[2] M. Righettoni, A. Schmid, A. Amann, and S. E. Pratsinis, "Correlations between blood glucose and breath components from portable gas sensors and PTR-TOF-MS," J. Breath Res., vol. 7, no. 3, p. 037110, Aug. 2013.

[3] Z. Ying, Y. Jiang, H. Qin, L. Zheng, and X. Du, "A study on QCM sensor for identification of acetone vapor," COMPEL - Int. J. Comput. Math. Electr. Electron. Eng., vol. 29, no. 2, pp. 477-483, Mar. 2010.

[4] G. Lal and D. C. Tiwari, "Investigation of nanoclay doped polymeric composites on piezoelectric Quartz Crystal Microbalance (QCM) sensor,” Sens. Actuators B Chem., vol. 262, pp. 64-69, Jun. 2018.

[5] H. Zhang, Y. Cen, Y. Du, and S. Ruan, "Enhanced Acetone Sensing Characteristics of ZnO/Graphene Composites," Sensors, vol. 16, no. 11, p. 1876, Nov. 2016.

[6] D. Wang et al., "CO2-sensing properties and mechanism of nano- $\mathrm{SnO}_{2}$ thick-film sensor," Sens. Actuators $B$ Chem., vol. 227, pp. 73-84, May 2016.

[7] M. Procek, A. Stolarczyk, T. Pustelny, and E. Maciak, "A Study of a QCM Sensor Based on $\mathrm{TiO}_{2} \mathrm{Nanostructures}$ for the Detection of $\mathrm{NO}_{2}$ and Explosives Vapours in Air," Sensors, vol. 15, no. 4, pp. 9563-9581, Apr. 2015. 
[8] J. Huang, T. Yang, Y. Kang, Y. Wang, and S. Wang, "Gas sensing performance of polyaniline/ZnO organicinorganic hybrids for detecting VOCs at low temperature," J. Nat. Gas Chem., vol. 20, no. 5, pp. 515-519, Sep. 2011.

[9] P. Kumar, K. L. Woon, W. S. Wong, M. S. Mohamed Saheed, and Z. A. Burhanudin, "Hybrid film of single-layer graphene and carbon nanotube as transparent conductive electrode for organic light emitting diode," Synth. Met., vol. 257, p. 116186, Nov. 2019.

[10] V. V. Quang, V. N. Hung, L. A. Tuan, V. N. Phan, T. Q. Huy, and N. V. Quy, "Graphene-coated quartz crystal microbalance for detection of volatile organic compounds at room temperature," Thin Solid Films, vol. 568, pp. 612, Oct. 2014.

[11] R. Ahmad et al., "Highly Efficient Non-Enzymatic Glucose Sensor Based on CuO Modified Vertically-Grown ZnO Nanorods on Electrode," Sci. Rep., vol. 7, no. 1, p. 5715, Dec. 2017.

[12] H. S. S. R. Matte, K. S. Subrahmanyam, and C. N. R. Rao, "Synthetic Aspects and Selected Properties of Graphene," Nanomater. Nanotechnol., vol. 1, p. 5, Jul. 2011.

[13] G. Lu, L. E. Ocola, and J. Chen, "Reduced graphene oxide for room-temperature gas sensors," Nanotechnology, vol. 20, no. 44, p. 445502, Nov. 2009.

[14] D. Sun, Y. Luo, M. Debliquy, and C. Zhang, "Graphene-enhanced metal oxide gas sensors at room temperature: a review," Beilstein J. Nanotechnol., vol. 9, pp. 2832-2844, Nov. 2018.

[15] A. A. Nawawi, S. M. Sultan, S. F. A. Rahman, P. I. Khalid, and S. H. Pu, "Reverse biased nanocrystalline graphite (NCG)/p-Si schottky junction for methane gas sensor," Indones. J. Electr. Eng. Comput. Sci., vol. 15, no. 3, p. 6, 2019.

[16] H. J. Park et al., "Highly flexible, mechanically stable, and sensitive $\mathrm{NO}_{2}$ gas sensors based on reduced graphene oxide nanofibrous mesh fabric for flexible electronics," Sens. Actuators B Chem., vol. 257, pp. 846-852, Mar. 2018.

[17] H.-F. Zhang, B.-Y. Ning, T.-C. Weng, D.-P. Wu, and X.-J. Ning, "What retards the response of graphene based gaseous sensor," Sens. Actuators Phys., vol. 295, pp. 188-192, Aug. 2019.

[18] I. Torres, S. Mehdi Aghaei, A. Rabiei Baboukani, C. Wang, and S. Bhansali, "Individual Gas Molecules Detection Using Zinc Oxide-Graphene Hybrid Nanosensor: A DFT Study," C, vol. 4, no. 3, p. 44, Aug. 2018.

[19] S. N. Che Azmi, S. F. Abd Rahman, and A. M. Hashim, "Back-to-Back Schottky Diode from Vacuum Filtered and Chemically Reduced Graphene Oxide,” Indones. J. Electr. Eng. Comput. Sci., vol. 10, no. 3, p. 897, Jun. 2018.

[20] B. Garrido, J. Samitier, J. R. Morante, L. Fonseca, and F. Campabadal, "Influence of the silicon wafer cleaning treatment on the $\mathrm{Si} / \mathrm{SiO}_{2}$ interfaces analyzed by infrared spectroscopy," Appl. Surf. Sci., vol. 56-58, pp. 861-865, Jan. 1992.

[21] H.-S. Lee et al., "Use of the quartz crystal microbalance to monitor ligand-induced conformational rearrangements in HIV-1 envelope protein gp120," Anal. Bioanal. Chem., vol. 396, no. 3, pp. 1143-1152, Feb. 2010.

[22] S. K. Vashist and P. Vashist, "Recent Advances in Quartz Crystal Microbalance-Based Sensors," J. Sens., vol. 2011, pp. 1-13, 2011.

[23] M. M. Ayad, N. Salahuddin, and I. M. Minisy, "Detection of some volatile organic compounds with chitosancoated quartz crystal microbalance," Des. Monomers Polym., vol. 17, no. 8, pp. 795-802, Nov. 2014.

[24] D. Zhang, J. Liu, H. Chang, A. Liu, and B. Xia, "Characterization of a hybrid composite of $\mathrm{SnO}_{2}$ nanocrystaldecorated reduced graphene oxide for ppm-level ethanol gas sensing application," RSC Adv., vol. 5, no. 24, pp. 18666-18672, 2015.

[25] M. S. Eluyemi et al., "Synthesis and Characterization of Graphene Oxide and Reduced Graphene Oxide Thin Films Deposited by Spray Pyrolysis Method," Graphene, vol. 05, no. 03, pp. 143-154, 2016.

[26] M. A. A. Rosli, P. T. Arasu, A. S. M. Noor, H. N. Lim, and N. M. Huang, "Reduced Graphene Oxide nanocomposites layer on fiber optic tip sensor reflectance response for sensing of aqueous ethanol," J. Eur. Opt. Soc.Rapid Publ., vol. 12, no. 1, p. 22, Dec. 2016.

[27] S. Gayathri, P. Jayabal, M. Kottaisamy, and V. Ramakrishnan, "Synthesis of few layer graphene by direct exfoliation of graphite and a Raman spectroscopic study," AIP Adv., vol. 4, no. 2, p. 027116, Feb. 2014.

[28] A. Bhaumik and J. Narayan, "Wafer scale integration of reduced graphene oxide by novel laser processing at room temperature in air," J. Appl. Phys., vol. 120, no. 10, p. 105304, Sep. 2016.

[29] T. Lin, X. Lv, Z. Hu, A. Xu, and C. Feng, "Semiconductor Metal Oxides as Chemoresistive Sensors for Detecting Volatile Organic Compounds," Sensors, vol. 19, no. 2, p. 233, Jan. 2019.

[30] R. P. Antony, L. K. Preethi, B. Gupta, T. Mathews, S. Dash, and A. K. Tyagi, "Efficient electrocatalytic performance of thermally exfoliated reduced graphene oxide-Pt hybrid," Mater. Res. Bull., vol. 70, pp. 60-67, Oct. 2015.

[31] K. S. Novoselov et al., "Two-dimensional gas of massless Dirac fermions in graphene," Nature, vol. 438, no. 7065, pp. 197-200, Nov. 2005.

[32] S. Basu and P. Bhattacharyya, "Recent developments on graphene and graphene oxide based solid state gas sensors," Sens. Actuators B Chem., vol. 173, pp. 1-21, Oct. 2012.

[33] Xianhe Huang, Qingsong Bai, Jianguo Hu, and Dong Hou, "A Practical Model of Quartz Crystal Microbalance in Actual Applications," Sensors, vol. 17, no. 8, p. 1785, Aug. 2017.

[34] H. J. Yoon, D. H. Jun, J. H. Yang, Z. Zhou, S. S. Yang, and M. M.-C. Cheng, "Carbon dioxide gas sensor using a graphene sheet," Sens. Actuators B Chem., vol. 157, no. 1, pp. 310-313, Sep. 2011.

[35] X. Huang, Q. Bai, W. Pan, and J. Hu, "Quartz Crystal Microbalance with Approximately Uniform Sensitivity Distribution,” Anal. Chem., vol. 90, no. 11, pp. 6367-6370, Jun. 2018. 
[36] "High-Resolution Gas/Odor Sensors Using High-Frequency Quartz Crystal Microbalance,” Sens. Mater., p. 131, 2014.

\section{BIOGRAPHIES OF AUTHORS}

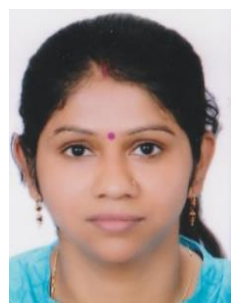

Monika Gupta is pursuing a Ph.D. in Electrical and Electronic Engineering Department from Universiti of Teknologi PETRONAS, Malaysia. She received her master's degree in Electronics Engineering from Harcourt Butler Technological University, Kanpur, India in 2010 and Bachelor's degree from Uttar Pradesh Technical University, India in 2006. She has more than $5++$ years of working experience in academics. Her research interest includes nanodevices and gas sensors.

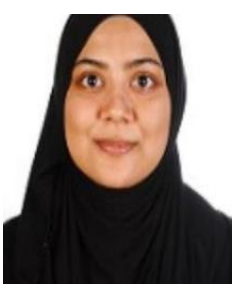

Nurul Athirah received her bachelor's degree in Materials Engineering from the University of Malaya (UM) in 2014 and a Masters in Engineering Science from the same university in 2018. She is currently doing her Ph.D. in Electrical and Electronic in University Technology Petronas (UTP). Her research interests are nanotechnology and sensor device.

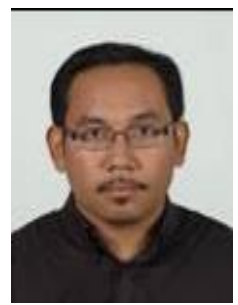

Hawari Huzein Fahmi received a degree in Electrical and Electronics Engineering from the University Science of Malaysia (USM) in 1999 and a Masters in Electronics Engineering from University Technology of Malaysia (UTM) in 2008. He completed his Ph.D. at Universiti Malaysia Perlis (UniMAP), in Mechatronics Engineering. As for his working experience, he has 14++ years of working experience in Intel Malaysia especially in Computer Architecture, Motherboard Technology, and Solid State Devices. His range of expertise ranging from Technical Training, Product Engineering, Outsource Management to System Validation. He is currently attached to the Department of Electrical and Electronic Engineering, Universiti Teknologi PETRONAS, Malaysia. His research and interest fields are MEMS, gas sensors, nanodevices, sensor system and the Internet of Things (IoT). 